\title{
Effect of Fiber Orientation on the Tensile Properties of Jute Epoxy Laminated Composite
}

\author{
M. R. Hossain ${ }^{1,2, *}$, M. A. Islam ${ }^{1}$, A. V. Vuurea ${ }^{2}$, and I. Verpoest ${ }^{2}$ \\ ${ }^{1}$ Department of Materials \& Metallurgical Engineering, Bangladesh University of Engineering and \\ Technology, Dhaka-1000, Bangladesh \\ ${ }^{2}$ Department of Metallurgy and Materials Engineering, Katholieke Universiteit Leuven, \\ Kasteelpark, Arenberg 44, bus 2450, 3001 Heverlee, Belgium
}

Received 4 May 2012, accepted in final revised form 25 October 2012

\begin{abstract}
Jute, the pride of Bangladesh, has gained interest in the composite field due to its superior specific properties compared to artificial manmade fibers like glass, kevlar, etc. In this study, jute composites made with the vacuum assisted resin infiltration (VARI) techniques were investigated. Jute fiber preform stacking sequences were $(0 / 0 / 0 / 0), 0 /+45 \%-45 \%$ and $0 / 90^{\circ} / 90^{\circ} / 0$. For all cases, a total of $25 \%$ volume fraction of jute fiber was incorporated. The developed composites were characterized by tensile tests and the experimental results thus obtained were compared with that of the theoretical values. After tensile tests, fracture surfaces were cut and observed under high resolution FEG SEM. In the case of 0/0/0/0 and $0 /+45 \%-45 \%$ lamina composites, longitudinal tensile strength has been found to be higher than that of the transverse direction. However, for $0 / 90^{\circ} / 90^{\circ} / 0$ lamina composites, tensile strengths in both directions were very close to each other. For all developed composites, experimental results revealed that the tensile properties of the developed composites strongly depend on the tensile strength of jute fiber and that the tensile properties of jute fiber are very much defect-sensitive. Finally, a discussion of the tensile behaviors of the composites is initiated in terms of the fracture morphologies observed under the SEM.
\end{abstract}

Keywords: Jute laminate; UD; Interface; VARI.

() 2013 JSR Publications. ISSN: 2070-0237 (Print); 2070-0245 (Online). All rights reserved. doi: http://dx.doi.org/10.3329/jsr.v5i1.10519 J. Sci. Res. 5 (1), 43-54 (2013)

\section{Introduction}

Jute, a growing sector in Bangladesh, has occupied a place in composite field quite a decade ago. Its low cost, versatility in textile field, eco-friendly nature and moderate mechanical properties have outnumbered the applications of some artificial fibers like glass, kevlar, etc. in many composite applications. However, biodegradability and environment friendly behaviors of jute are just interrupted with the hydrophilic nature,

\footnotetext{
* Corresponding author: hrashnal@ hotmail.com
} 
which in turn affects the composite mechanical properties as well as the applications of jute fiber reinforced composites [1,2].

Jute like natural fiber has good specific mechanical properties, although its tensile strength is extremely defect and span sensitive. One of the most sensitive defects that affect the tensile strength of the jute fiber is its lumen or hollow space in it. Lumen present in the BWB jute fiber can act as a source of defect in the composite and initiates failure. The severity of these effects on tensile strength depends on the geometry and volume fraction of the lumen. At the same time, the volume fraction of lumen or availability of lumen of critical size and shape also depends on the span size of the jute fibers. As a result, tensile properties are usually corrected for getting their average values [3-6].

Jute fiber bundle has a lot of entanglement. So, it is very difficult to make unidirectional (UD) preform of the jute fiber manually with bare hand under dry condition [7]. On the other hand, hackling under dry or wet condition introduces more defects in the fiber. At the same time, jute fiber becomes gradually thinner [8]. For this reason, woven jute fabric is usually preferred. However, in this case, anisotropic properties might also arrive [8, 9].

Due to natural twist and entanglement in jute like natural fibers, they are stuffed with linseed oil. These stuffed jute fibers are then hackled by special type of machine and yarns are made prior to woven fabric preparation [8]. But, the hydrophilic nature of jute is interfered in the presence of oil. Moreover, the presence of oil gives very inferior interfaces during the reinforcement of both thermoplastic and thermoset polymers. So, additional washing and drying steps become very essential before composite preparation $[10,11]$. As a result, UD jute preform or roving preparation has become a valuable step, which is gaining a great importance nowadays.

To achieve multidirectional isotropic behaviors, proper fiber orientation in different angle is necessary, which can only be done by multiply laminate preparation [12]. Stacking the UD ply in different angles gives composite with anisotropic physical and mechanical properties [13]. However, multiply composites of superior and moderately superior mechanical properties, with up to $50 \%$ volume fraction of fiber reinforcement, are possible to fabricate through conventional procedures like compression molding and hand-lay-up for jute like natural fiber [14].

Prepegging, resin transfer molding (RTM) and vacuum assisted resin infiltration (VARI, similar to RTM, but differs in infiltration pressure) for making thermoset polymer based composites $[14,15]$. Although, these processes are quite a decade old for artificial fiber reinforced composite, but its versatility still attracted the natural fiber composite researchers to utilize these techniques [16]. Therefore, a combination of techniques to make UD jute fiber preform along with suitable composite fabrication is necessary for making continuous jute-thermoset prepreg or finished product for various applications.

\section{Experimental}

\subsection{Materials and methods}

In this research work retted, water washed and sun dried Bangla White Grade B (BWB) jute was collected from Bangladesh Jute Research Institute (BJRI). From the bunch of the 
collected jute, single jute fibers were separated and tensile tests were carried out. The strength values obtained from single jute fiber tensile test are not identical from fiber to fiber. As a result, the scatter band is very wide. To avoid this problem, many researchers in this field corrected the experimental values by some mathematical relationships [6]. In this research work, single fiber tensile test results were also corrected following them. For the fabrication of the jute fiber reinforced composites, four layer laminate preforms of size $400 \mathrm{mmX} 400 \mathrm{~mm}$ were made with jute fiber bunch and stacked them in the following sequence $0 / 0 / 0 / 0,0 /+45^{\circ} /-45^{\circ} / 0$ and $0 / 90^{\circ} / 90^{\circ} / 0$ as shown in Fig. 1. It is to be mentioned here that the jute fibers were wetted with water to make the preforms. After making the preforms, they were dried at $60^{\circ} \mathrm{C}$ overnight prior to composite fabrication.
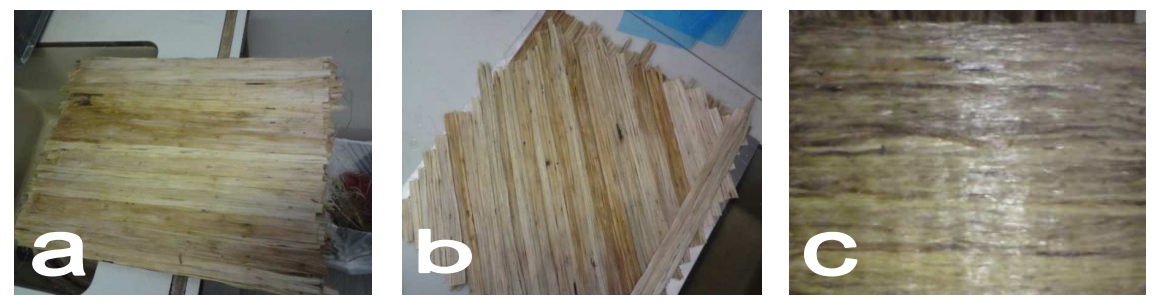

Fig. 1. Stacking sequence of BWB jute preform; a) 0/0/0/0, b) $0 /+45^{\circ} /-45^{\circ} / 0$ arid c) $0 / 90^{\circ} / 90^{\circ} / 0$.

Before the composite fabrication, epoxy resin (Epikote 828Lvel, Bisphenol A and Epichlorehydrin) and diaminocyclohexane hardener were mixed together. Then jute epoxy based composite was made with VARI technique as shown in Fig. 2.
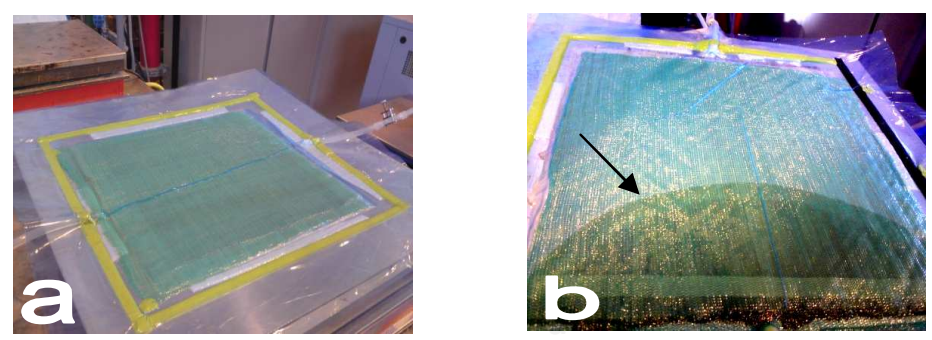

Fig. 2. VARI setup and resin front during jute epoxy composite fabrication process; a) VARI setup and b) resin front (indicated by arrow).

It is to be noted that VARI is a well accepted technique for composite fabrication. In this research work, the preform was put inside the vacuum bag that was kept fixed with the mold surface. Then vacuum was applied to remove inside air along with free moisture. In order to accelerate the vacuum process, the preform was heated to $40^{\circ} \mathrm{C}$ and the process was run for half an hour. Then resin was infiltrated under vacuum. As soon as the infiltration was completed, both sides of the vacuum bag were clamped and 
temperature was increased to $135^{\circ} \mathrm{C}$ at a heating rate of $5-10^{\circ} \mathrm{C} / \mathrm{min}$ for necessary curing. At this temperature, the composite was fully cured. Following this technique, $25 \%$ volume fraction of BWB jute fiber composites were made for different fiber orientations.

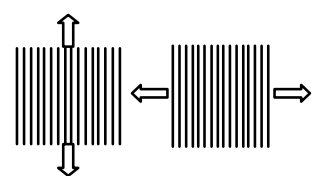

a

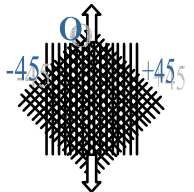

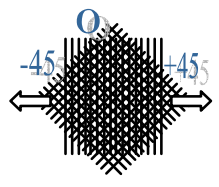

b

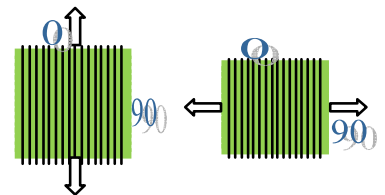

C

Fig. 3. Stacking sequence and tensile loading direction (ASTM D3039) of jute epoxy composite; a) $0 / 0 / 0 / 0$, b) $0 /+45 \%-45 \%$ and c) $0 / 90 \% / 90 \%$.

Tensile specimens were prepared following ASTM D3039 standard (dimensions of specimen: length $250 \mathrm{~mm}$, thickness $4 \pm 0.5 \mathrm{~mm}$, width $15 \pm 1.5 \mathrm{~mm}$, gage length $100 \mathrm{~mm}$ ). The specimens were cut using small toothed table saw and finishing was done with 1200 grade emery paper and stored over night in an oven at $50^{\circ} \mathrm{C}$ prior to test. Fig. 3 shows the loading direction of the tensile test specimens. All tensile tests were carried out with the help of Instron universal testing machine (model 4467) having $30 \mathrm{kN}$ load cell attached in it and extensometer gage length $50 \mathrm{~mm}$. It is to be mentioned that all tensile tests were performed at a cross-head speed of $0.85 \mathrm{~mm} / \mathrm{min}$. For all cases at least 5 specimens were tested.

After tensile tests, composite fracture surfaces were cut off and they were observed under a very high resolution FEG (field emission gun) SEM of model PHILIPS XL30 FEG.

\section{Results and Discussion}

Tensile tests of BWB jute fiber epoxy composite were carried out in the computer controlled (Instron data acquisition software) universal testing machine. The stress strain curves thus generated during the tensile tests are represented in Fig. 4.
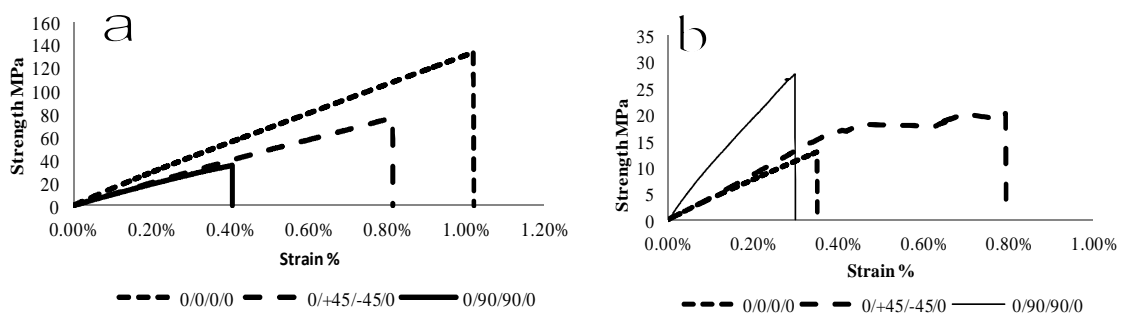

Fig. 4. Typical stress strain curve of BWB jute epoxy composite; a) longitudinal and b) transverse direction. 
Table 1 shows the summary of the longitudinal tensile test results. A common remark is that the strength and strain to failure in the principal $\left(0^{\circ}\right)$ loading direction has a decreasing trend with increasing lamina angle. The tensile properties of the developed composites in the transverse directions are presented in Table 2. The common remark from Table 2 is that the strength values in the transverse direction have an increasing trend with the increasing jute fiber angle.

Table 1. Longitudinal tensile behavior of laminates.

\begin{tabular}{lllllll}
\hline $\begin{array}{l}\text { Lamina } \\
\text { type }\end{array}$ & $\begin{array}{l}\text { Strength } \\
\mathrm{MPa}\end{array}$ & $\mathrm{SD}$ & $\begin{array}{l}\text { Strain to } \\
\text { failure }\end{array}$ & $\mathrm{SD}$ & $\begin{array}{l}\text { Young's } \\
\text { modulus GPa }\end{array}$ & SD \\
\hline $0-0$ & 112.69 & 18.31 & $0.82 \%$ & $0.17 \%$ & 14.59 & 2.28 \\
$0-45$ & 64.31 & 13.18 & $0.64 \%$ & $0.15 \%$ & 10.46 & 0.56 \\
$0-90$ & 42.54 & 6.42 & $0.43 \%$ & $0.05 \%$ & 11.13 & 1.47 \\
\hline
\end{tabular}

Table 2. Transverse tensile behavior of laminates.

\begin{tabular}{|c|c|c|c|c|c|c|c|}
\hline $\begin{array}{l}\text { Lamina } \\
\text { type }\end{array}$ & $\begin{array}{l}\text { Strength } \\
\mathrm{MPa}\end{array}$ & SD & $\begin{array}{l}\text { Strain } \\
\text { failure }\end{array}$ & to & SD & $\begin{array}{c}\text { Young's } \\
\text { modulus GPa }\end{array}$ & SD \\
\hline $0-0$ & 11.06 & 3.30 & $0.35 \%$ & & $0.04 \%$ & 3.25 & 0.62 \\
\hline $0-45$ & 21.33 & 2.08 & $0.80 \%$ & & $0.38 \%$ & 4.46 & 0.64 \\
\hline $0-90$ & 39.10 & 10.85 & $0.53 \%$ & & $0.19 \%$ & 8.97 & 0.74 \\
\hline
\end{tabular}

\subsection{Mechanical properties of UD and 0-90 composites}

Before going to in-depth discussion for the UD and 0-90 composites we must know the tensile properties of BWB jute fiber and the epoxy matrix separately, which are shown in Table 3.

Table 3. Average tensile properties of epikote 828 Lvel epoxy resin and BWB jute fiber.

\begin{tabular}{llll}
\hline Materials & $\begin{array}{l}\text { Strength } \\
\mathrm{MPa}\end{array}$ & $\begin{array}{l}\text { Young's modulus } \\
\mathrm{GPa}\end{array}$ & $\begin{array}{l}\text { Strain to failure } \\
\%\end{array}$ \\
\hline $\begin{array}{l}\text { Epoxy (Epikote } \\
\text { 828Lvel) }\end{array}$ & $81.72 \pm 13.16$ & $3.89 \pm 0.53$ & $2.23 \pm 0.50$ \\
BWB jute & $\begin{array}{l}844.72 \pm 142.47 \\
\text { (extrapolated) }\end{array}$ & $\begin{array}{l}55.66 \pm 2.11 \\
\text { (corrected for span } \\
\text { length) }\end{array}$ & $1.67 \pm 0.31$ \\
\hline
\end{tabular}


The strength of jute fiber is dependent on the fiber structure, its flaw density, griping pressure and slippage during tension test and strain rate. As a result, jute fiber shows a wide scatter band in tensile strength as like as other natural fibers. In order to obtain the maximum possible tensile strength value of the fiber, average tensile strength values of various fiber spans were plotted first. From this plot, the maximum possible tensile strength value was obtained by means of extrapolation on to the Y-axis. Consequently, during the test a range of stiffness values for BWB jute fiber were obtained. But, for a single material the stiffness value should be one unique value rather than a range. In order to eradicate the effect of these flaws and additional factors on stiffness values of jute fiber a correction procedure developed by other $[5,6]$ was followed.

In the case of composites two or more materials of different properties are mixed together to get required properties, which are usually different from that of the constituent materials. For the determination of mechanical properties of composites, rule of mixture provides very useful idea for the researchers. One of the important mathematical relations for this is given below:

$$
\sigma_{c 1}=\sigma_{f} V_{f}+\sigma_{m} V_{m} \quad[\sigma \text { stands for stress }]
$$

where subscript $c, f$, and $\mathrm{m}$ stand for composite, fiber and the matrix and $V$ is the volume fraction.

As per the rule of mixture the calculated composite strength for UD composite should be $272.47 \mathrm{MPa}$ for 25 volume percentage BWB jute reinforced epoxy. But the experimental value is $112.69 \mathrm{MPa}$, which is only $41 \%$ of the theoretical value. This type of low efficiency of fiber strengthening has also been mentioned by other [17]. The reasons behind the decreased value of tensile strength of the composite are the presence of defects in both the matrix and fiber of various concentrations and geometries. Fig. 5 indicates the types of defects that were observed in BWB jute fiber during the research work.
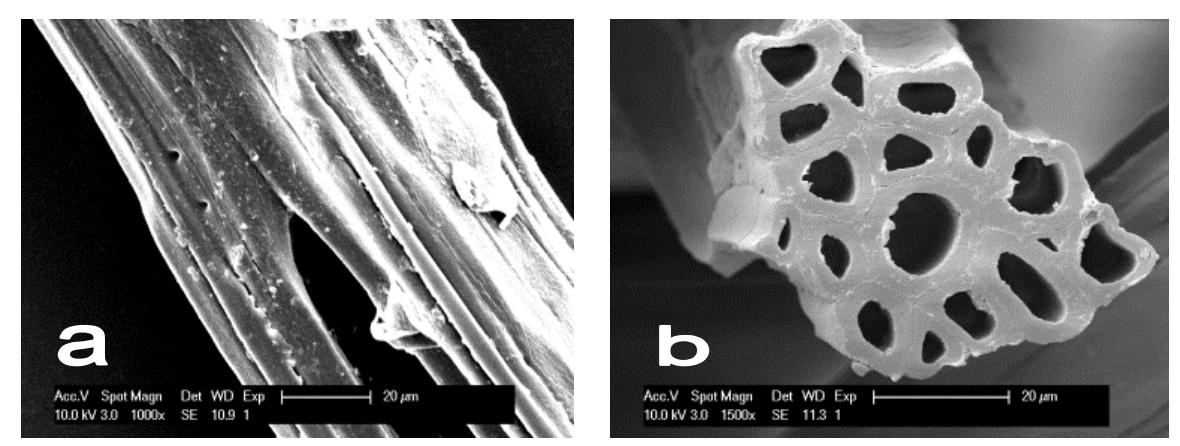

Fig. 5. SEM micrographs showing the defects in BWB jute fiber used; a) lateral defect and b) $x$ sectional defect. 


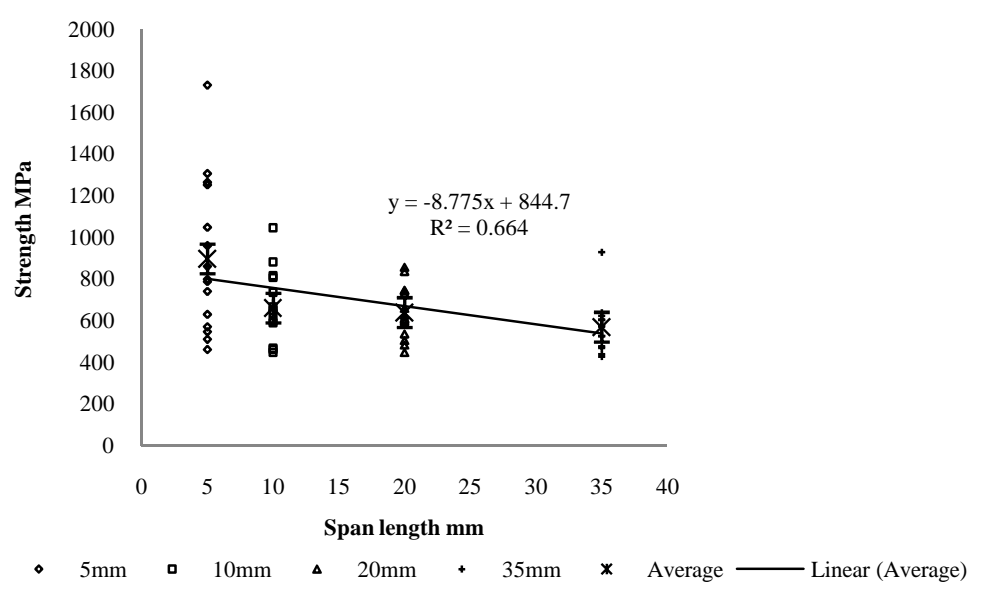

Fig. 6. Tensile strength variations of BWB jute relative to span lengths.

Fig. 6 represents the strength of BWB jute fiber as a function of span lengths. From this figure, it is very clear that the tensile strength of the jute fiber decreases with increase in the span length. Defoirdt et al. [6] also observed this type of effect in the case of different natural fibers. From this figure, another observation is that the scatter for each span is relatively higher for lower span length compared to that of the higher span length. In Fig. 6, the range of strength values were plotted for each span length. From this trend line (also from the trend equation given in Fig. 6), it is clear that the average strength for $5 \mathrm{~mm}$ span is around $800 \mathrm{MPa}$, but the extrapolated maximum value is 844.72 (when the span size is very small, i.e. close to zero).

Here, it is important to mention that it is very difficult and in many cases, impossible to develop engineering product to be defect free and that the possibility of having higher proportion or larger size defects in long span test specimen is also high. Moreover, it is also obvious that the surface conditions of jute fibers are not always identical. As a result, compatibility and adhesion between jute fiber and the matrix vary, which also contributes to lower tensile strength of the developed composites.

Similar to the longitudinal tensile strength, tensile strengths in the transverse direction is also lower than that of the theoretical values. From Table 2, it is clear that, in transverse direction the tensile strength is significantly lower than that of the longitudinal direction. The reason behind this is that the fiber-matrix interfaces and defects inside the jute fiber mostly dominate the tensile strength of the composites. In this type of composites, especially with inhomogeneous fiber content, lack of bonding between matrix/fiber interfaces, voids, inherent defects of the jute fiber, etc. seriously degrade the tensile strength of the composite $[18,19]$. These defects mainly generate during the fabrication process and are accumulated mostly around the fiber-matrix interface [20,21]. As a result of the combined degrading effects, the experimental tensile strength of the composites in 
the transverse direction becomes significantly lower than that of the longitudinal direction. So, in any direction, the maximum fiber strength efficiency has not been achieved [22, 23].

The higher values of tensile strengths in the longitudinal direction can also be explained by its fracture morphologies. For 0/0 lamina composites, two step type of fracture morphology has been observed. At first, debonding at the matrix/fiber interfaces took place. Then matrix was broken because of its relatively lower tensile strength. At last, jute fiber having relatively higher tensile strength value was broken. This phenomenon is shown in Fig. 7. As the jute fiber has a high tensile strength, so the composite showed higher tensile strength in the longitudinal direction.

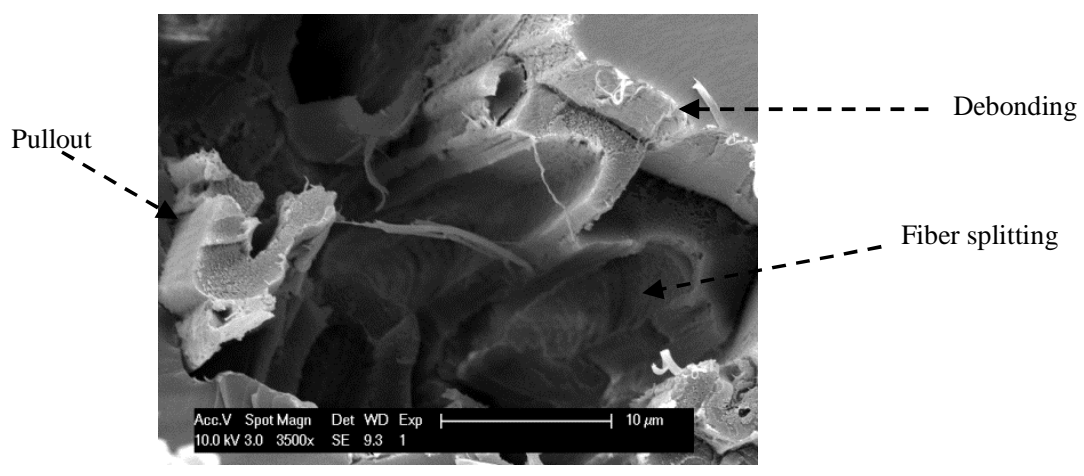

Fig. 7. Composite failure under longitudinal loading.

In the case of transverse direction, tensile failure of $0 / 0$ lamina jute fiber composites fiber slicing (indicated by circle Fig. 8a) and debonding (indicated by arrow Fig. 8b) at fiber-matrix interfaces have been found to be dominant modes of fracture, Fig. 8. Here, a significant proportion of the load bearing section is covered by the weak fiber/matrix interface. As a result, for 0/0 lamina of jute fiber composites, a drastic decrease in tensile strength was observed. The summary of tensile failure steps are shown schematically in Fig. 9.
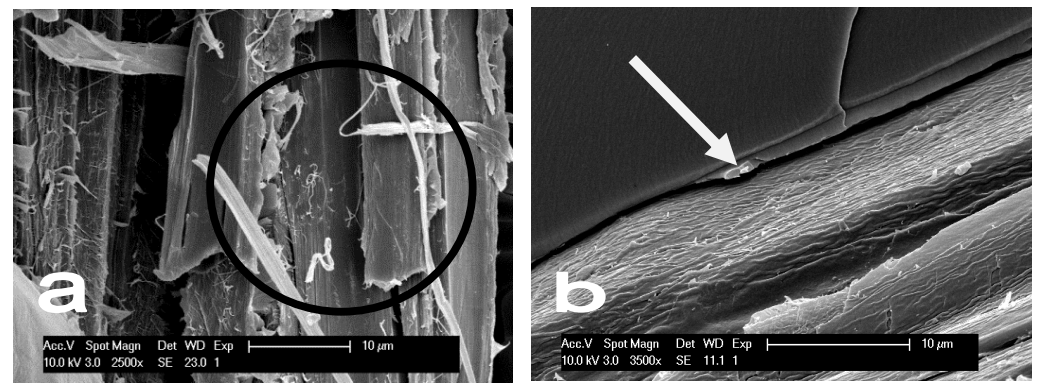

Fig. 8. Fiber and matrix failure under transverse tensile load; a) fiber slicing and b) debonding. 


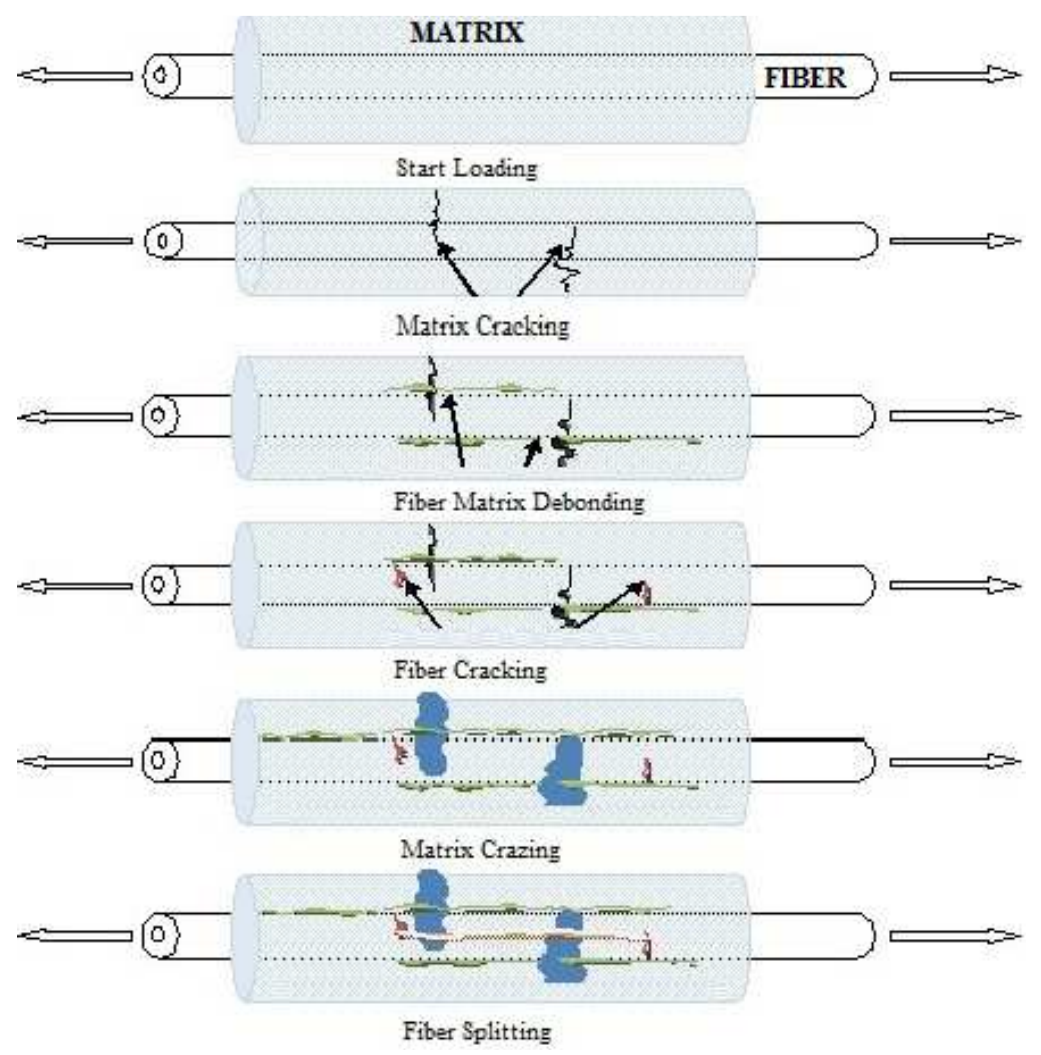

Fig. 9. Schematics of sequential failure events of BWB jute epoxy composite.

\subsection{Mechanical properties of $0 /+45 /-45 / 0$ composite}

In the case of $0 /+45 /-45 / 0$ composites, the longitudinal tensile strength are inferior to that of UD composite. The reason behind this is that in UD both the relatively high strength jute fiber and weaker epoxy matrix control the tensile strength. However, in the case of $0 /+45 /-45 / 0$ fiber-matrix interfaces mainly dominate the composite strength and that the concentration of defects are higher on these interfaces. As a result, for $0 /+45 /-45 / 0$ composite, the tensile strengths are poor in longitudinal directions.

On the other hand, the transverse strength of the 0/+45/-45/0 composite, showed higher value than the UD composite. The reason behind this is that in UD most of the defects are at the fiber matrix interface. But, in the case of $0 /+45 /-45 / 0$ composite the $+45 /-45$ ply acts as a source of resistance in $+45^{\circ}$ and $-45^{\circ}$ directions. As a result, for $0 /+45 /-45 / 0$ composite, the transverse tensile strength is slightly higher than UD in the transverse direction. 
For laminates, the simple rule of mixture is not applicable. In case of $0 /+45 /-45 / 0$ composite, there are two interior layers (respectively, $+45^{\circ}$ and $-45^{\circ}$ ), where the interior layer behaves differently under stress. Their responses are also different and complex. In order to avoid the complex behavior of reinforcing fibers in the composite, the experimental results have been explained in terms of physical morphologies of the fibers and fracture surfaces of the composites.

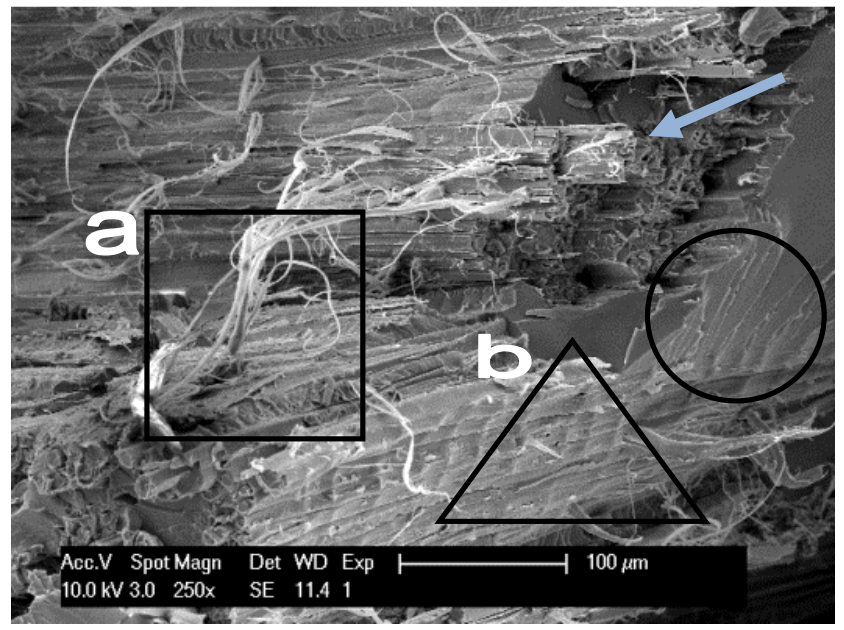

Fig. 10. Fracture surface of 0/+45/-45/0 composite laminate; a) fiber debris and b) share-lip type wavy surface.

Fig. 10 indicates the typical fracture surface of $0 /+45 /-45 / 0$ composite. From this figure, it is clear that failure is dominated by fiber-matrix and matrix-matrix shearing, matrix and fiber failure, and fiber-matrix interface failure. Fiber-matrix interface failure is indicated by shear-lip type wavy fracture surface (indicated by triangle) [24]. Some fiber pullout in $\pm 45^{\circ}$ direction is also observed (marked by arrows). Since there is fiber matrix shearing, so fiber debris is also observed on the fracture surface (indicated by square). Fig. 10 also indicates a large island of matrix (indicated by circle), which indicates that the fiber matrix distribution is non uniform. This non uniform fiber matrix distribution is also responsible for lower tensile property of the jute epoxy composite.

Spherulitic type of matrix failure around fiber indicates the presence of compressive force as shown in Fig. 11a (indicated by circle). This compressive zone is more brittle than the surrounding matrix. When tensile stress is applied this compressive zone shows the tendency of matrix cracking around the fiber (indicate by black arrow Fig. 11a). The presence of compressive force is confirmed by crazing zone around fiber, (indicated by rectangle in Fig. 11b). Additionally some brittle fiber failure was also observed as indicated with triangle in Fig. 11c. 

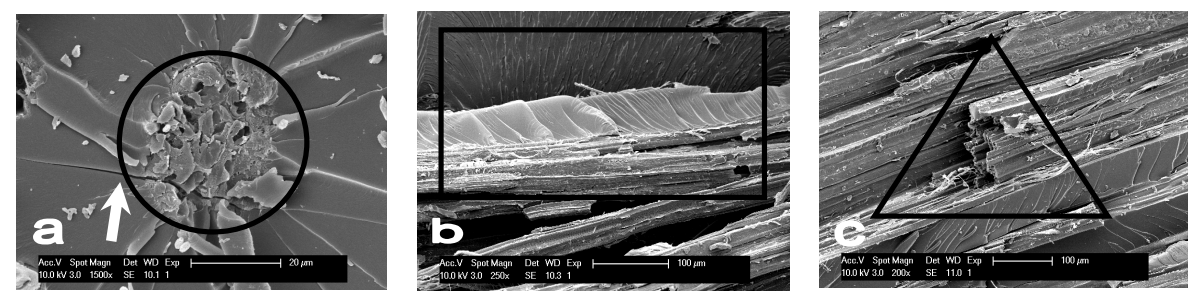

Fig. 11. Crazing of jute epoxy composite under transverse tensile loading a) spherulitic failure, b) crazing and c) Fiber failure.

\section{Conclusions}

In this research work, jute fiber reinforced epoxy matrix composites were developed by vacuum assisted resin infiltration (VARI) techniques with preformed stacking sequences $(0 / 0 / 0 / 0), 0 /+45^{\circ} / 45^{\circ} / 0$ and $0 / 90^{\circ} / 90^{\circ} / 0$. These composites were characterized by tensile tests and observation of fracture surfaces under high resolution FEGSEM. From this research work, the following conclusions are made.

a. In the case of $0 / 0 / 0 / 0$ and $0 /+45 \%-45 \%$ lamina composites, longitudinal tensile strength have been found to be higher than that of the transverse direction. However, for $0 / 90^{\circ} / 90^{\circ} / 0$ lamina composites, directional difference in tensile strength was not observed.

b. For all developed composites, experimental results revealed that the tensile properties of the developed composites are strongly dependent on the tensile strength of fiber and that the tensile properties of jute fiber are very much defect sensitive.

c. Concerning the tensile properties of composites, the theoretical values obtained from the rule of mixture deviate from that of the experimental values and that this deviation is more significant in the case of transverse direction.

d. Compressive fracture mode is attributed to spherulitic type appearance and crazing around jute fiber.

e. For UD jute epoxy composite the sequences of failure that were matrix cracking, matrix crazing at fiber-matrix interface, partial fiber breaking, fiber slicing and pullout from matrix. However, in transverse direction, it is composed of fiber slicing and formation of fiber debris.

\section{Acknowledgement}

The authors sincerely acknowledge the support of Department of Metallurgy and Materials Engineering, Katholieke Universiteit Leuven, Kasteelpark Arenberg 44 bus 2450, 3001 Heverlee, Belgium. 


\section{References}

1. A. Vazqueza and D. Plackett, Natural polymer sources (Woodhead Publishing Ltd \& CRC Press LLC, 2004) Chap. 7, pp. $123-125$.

2. X. Y. Liu and G. C. Dai, eXPRESS Polymer Lett. 1 (5), 299 (2007).

3. J. Y. Yu, Z. P. Xia, L. D. Cheng, L. F. Liu, and W.M. Wang, Composites: Part A 40, 54 (2009).

4. L. Y. Mwaikambo, Bio Resources 4 (2), 566 (2009).

5. J. Andersons, E. Porik, E. Sparninš, Composites Sci. Technol. 69, 2152 (2009). http://dx.doi.org/10.1016/j.compscitech.2009.05.010

6. N. Defoirdt, S. Biswas, De L.e Vriese, L. Q. Ngoc Tran, J. Van Acker, Q. Ahsan, L. Gorbatikh, A. Van Vuure, and I. Verpoest, Composites: Part A 41, 588 (2010).

7. S. P. Mishra, A Text Book of Fiber Science and Technology (New Age International (P) Limited, Publishers, 2005), Chap. 6, pp $94-99$

8. S. J. Eichhorn, C. A. Baillie, N. Zafeiropoulos, L. Y. Mwaikambo, M. P. Ansell, A. Dufresne, K. M. Entwistle, P. J. Herrera-Franco, G. C. Escamilla, L. Groom, M. Hughes, C. Hill, T. G. Rials, and P. M. Wild, J. Mater. Sci. 36, 2107 (2001). http://dx.doi.org/10.1023/A:1017512029696

9. K. Oksman, A. P. Mathew, R. Långström, B. Nyström, K. Joseph, Composites Sci. Technol. 69, 1847 (2009). http://dx.doi.org/10.1016/j.compscitech.2009.03.020

10. N. E. Zafeiropoulos, D. R. Williams, C. A. Baillie, and F. L. Matthews, Composites: Part A 33, 1083 (2002). http://dx.doi.org/10.1016/S1359-835X(02)00082-9

11. N. E. Zafeiropoulos, C. A. Baillie, and J. M. Hodgkinson, Composites: Part A 33, 1185 (2002). http://dx.doi.org/10.1016/S1359-835X(02)00088-X

12. F. Corrales, F. Vilaseca, M. Llop, J. Girones, J. A. Mendez, and P. Mutje, J. Hazard. Mater. 144, 730 (2007). http://dx.doi.org/10.1016/j.jhazmat.2007.01.103

13. P. D. Soden and M. J. Hinton, Composites Sci. Technol. 58, 1001 (1998). http://dx.doi.org/10.1016/S0266-3538(98)00074-8

14. S. Mouton, D. Teissandier, P. Sébastian, and J. P. Nadeau, Composites: Part A 41, 125 (2010). http://dx.doi.org/10.1016/j.compositesa.2009.09.027

15. J. Gassan, Composites: Part A 33, 369 (2002). http://dx.doi.org/10.1016/S1359-835X(01)00116-6

16. M. A. Maleque and F. Y. Belal, Arabian J. Sci. Eng. 32 2B, 359 (2006).

17. J. Gassan and A. K. Bledzki, Composites Sci. Technol. 59, 1303 (1999). http://dx.doi.org/10.1016/S0266-3538(98)00169-9

18. M. L. Costa, S. F. Muller de Almeida, and M. C. Rezende, Amer. Inst. Aero. Astron. J. 43 (6), 1336 (2005).

19. M. Jawaid, HPS. A. Khalil A. A, Bakar, A. Hassan, and R. Dungani, J. Composite Mater. 0(0), 1 (2012).

20. M. Boopalan, M. J. Umapathy, and P. Jenyfer, Silicon 4, 145 (2012). http://dx.doi.org/10.1007/s12633-012-9110-6

21. Z. Hong-yan, L. Di-hong, Z. Dong-xing, W. Bao-chang, and C. Yu-yong, Transac. Nonferrous Metals Soc. China 19, 470 (2009). http://dx.doi.org/10.1016/S1003-6326(10)60091-X

22. M. Hojo, M. Mizuno, T. Hobbiebrunken, T. Adachi, M. Tanaka, and S. K. Ha, Composites Sci. Technol. 69, 1726 (2009). http://dx.doi.org/10.1016/j.compscitech.2008.08.032

23. F. Jacquemin, Y. Abou Msallem, N. Boyard, A. Poitou, D. Delaunay, and S. Chate, Composites: Part A 41, 108 (2010).

24. http://research.ae.utexas.edu/mssm/KML BIO.htm, 12/1/2010. 